\title{
ASSOCIATION BETWEEN ALLERGIC RHINITIS AND ATOPIC BRONCHIAL ASTHMA: A STUDY OF 125 CASES
}

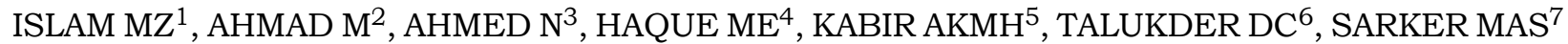

\begin{abstract}
:
Background: The aim of the present study was to see the prevalence of allergic comorbidities among the country's population and to increase impression of cost savings in the management of allergic comorbidities.

Methods: The study was done in the ENT outpatient department (OPD) of Dhaka Medical College Hospital, Dhaka, from January 2011 to January 2012 and 125 patients with allergic rhinitis with or without other allergies were selected over the period of study.

Results: Among the patients affected by allergic rhinitis along with other allergies $64 \%$ patients were male and 36\% were female. Maximum patients for both male and female were of the age group of 21-30 years (46\%). From the occupational point of view, students were mostly affected (34\% of the total patients). Maximum patients were suffering from allergic rhinitis along with atopic asthma and allergic conjunctivitis (22\%) and atopic asthma patients were about 55\% of the total patients of allergic rhinitis. Maximum patients of atopic asthma were of the age group of 21-30 years (48\%) for both male and female. 100\% asthmatic patients were suffering from chest tightness, $90 \%$ from cough, $87 \%$ from respiratory distress, $22 \%$ from wheeze $85 \%$ patients got positive stair test. $82 \%$ of the total patients of allergic rhinitis got eosinophilia, 68\% got hyperimmunoglobulinemia IgE and 25\% got eosinophil in their nasal smear. $87 \%$ patients with atopic asthma got eosinophilia, 83\% got hyperimmunoglobulinemia IgE and 45\% got eosinophil in their nasal smear- maximum patients (17\%) got the total circulatory eosinophil level from 901 to 1000 per cubic milimeter and maximum patients (32\%) got the IgE level from 100-300 per international unit. A good number of patients with atopic asthma selected randomly underwent spirometry test after having proper and adequate treatment of allergic rhinitis for few months along with bronchodilator for few weeks and they got no pulmonary obstruction.
\end{abstract}

Key words: Allergic rhinitis, Atopic bronchial asthma, Allergy.

J Dhaka Med Coll. 2013; 22(2) : 144-150.

\section{Introduction :}

Asthma and allergies, including allergic rhinoconjunctivitis and atopic dermatitis, are common throughout the world with a high burden of morbidity and cost. Most patients with asthma also have rhinitis. ${ }^{1}$ suggesting the concept of 'one airway, one disease'; a good fraction of patients with allergic rhinitis presents clinically demonstrable asthma even though a greater number has nonspecific nonspecific bronchial hyper reactivity ${ }^{2,3}$ supporting the term of 'ARIA' document. The global health problem allergic rhinitis is increasing in prevalence ${ }^{4-6}$.
However, in many instances, symptomes predominate in one organ and may be hidden in the other although they exist and truly, the common inflammatory process with the interconnected mechanisms well affect the upper and lower airways ${ }^{7-10}$. Environmental factors are mostly thought to be responsible for the world wide increase in allergic rhinitis and atopic asthma ${ }^{11}$ but there is undoubtedly a genetic component in allergic rhinitis as in other other allergic diseases ${ }^{12-18}$. Allergic rhinitis it self is a common risk factor for atopic asthma

1. Dr. Md Zahidul Islam, Consultant, Department of Otolaryngology \& Head-Neck Surgery, Dhaka Medical College Hospital. Dhaka.

2. Dr. Mohiuddin Ahmad, Associate Professor, Department of Respiratory Medicine, Dhaka Medical College, Dhaka.

3. Dr. Nafiza Ahmed, Associate Professor, Department of Skin \& VD, Dhaka Medical College, Dhaka.

4. Dr. Md. Emdadul Haque, Assistant Professor, Department of Skin \& VD, Dhaka Medical College, Dhaka.

5. Dr. AKM Humayon Kabir, Assisant Professor, Department of Medicine, DMCH, Dhaka

6. Dr. Debesh Chandra Talukder, Associate Professor, Dept. of Otolaryngology \& Head Neck Surgery, DMCH

7. Dr. Mohammad Abdul Sattar Sarker, Assistant Professor, Department of Medicine, Sir Salimullah Medical College, Dhaka

Correspondence: Dr. Md Zahidul Islam, Consultant, Department of Otolaryngology \& Head-Neck Surgery, Dhaka Medical College Hospital. Dhaka. Cell Phone: +8801918185926 
since the risk of asthma among the patients with allergic rhinitis was up to 300 times than among the patients without rhinitis $^{2}$; however, in case of severe asthma the role of rhinosinusitis should be carefully excluded hence it begets additional risk of asthma development. Allergic rhinitis induces nonspecific bronchial hyper reactivity exerting a unique physiological behaviour separating asthmactis and normal subjects. The presence of peripheral eosinophilia in patients with rhinosinusits indicates a high likelihood of extensive allerigc diseases-number of eosinophil increased in nasal membrane and blood 24 hours after bronchial exposure ${ }^{19-23}$. Epithelial cells represent the first barrier of both upper and lower respiratory tract and thus are the logical common targets for a comprehensive integrated therapecutic approach ${ }^{24-29}$. Association between allergies should be assessed from the socioeconomic aspect; risk of an asthma-related event for the treated group of rhinitis was about half that for untrcated group ${ }^{30-32}$ and patients receiving intranasal corticosteroids had a reduced risk for emergency asthma department visit in comparison to those who did not receive the treatment ${ }^{33}$. Yearly medical charges for those with asthma and concomitant allergic rhinitis was average $46 \%$ higher than for those with asthma alone ${ }^{38}$. The age of onset of atopy may be an important confounding factor for the development of asthma and rhinitis or rhinitis alone---atopy acquired at an early age, before the age of 6 years, is an important predictive factor for asthma continuing into late childhood whereas atopy acquired later was only associated with seasonal allergic rhinitis ${ }^{23,27,32,33}$.

\section{Methods:}

The study was carried out ENT out patient department of Dhaka Medical College Hospital, Dhaka, from January 2011 to January 2012 and 125 patients of clinically diagnosed allergic rhinitis with or without other allergies were selected over the period.

\section{Results:}

Table- I

Age and sex distribution of the patients with allergic rhinitis and other allergies $(n=125)$

\begin{tabular}{lccc}
\hline Age in years & \multicolumn{3}{c}{ Number of the patients } \\
& Male & Female & Total \\
\hline $01-10$ & 7 & 1 & 8 \\
$11-20$ & 11 & 9 & 20 \\
$21-30$ & 41 & 15 & 56 \\
$31-40$ & 10 & 9 & 19 \\
$41-50$ & 5 & 5 & 10 \\
$51-60$ & 4 & 5 & 9 \\
$60-80$ & 2 & 1 & 3 \\
\hline Total & $80(64 \%)$ & $45(36 \%)$ & 125 \\
\hline
\end{tabular}

Table-II

Occupational particulars of the patients $(n=125)$

\begin{tabular}{lc}
\hline Name of the occupation & $\begin{array}{c}\text { Number of } \\
\text { the patients }\end{array}$ \\
\hline Service holder & 30 \\
Businessman & 23 \\
Student & 41 \\
Agriculturist & 7 \\
Housewife & 19 \\
Others & 5 \\
\hline Total= & 125 \\
\hline
\end{tabular}

Table-III

Symptomes prevalence among the patients $(n=125)$

\begin{tabular}{lccc}
\hline Symptomes & \multicolumn{3}{c}{ Number of the patients } \\
& Male & Female & Total \\
\hline Rhinitis with asthma with conjunctivitis with dermatitis & 6 & 4 & 10 \\
Rhinitis with asthma with conjunctivitis & 18 & 9 & 27 \\
Rhinitis with asthma with dermatitis & 2 & 2 & 4 \\
Rhinitis with conjunctivitis with dermatitis & 3 & 1 & 4 \\
Rhinitis with asthma & 18 & 8 & 26 \\
Rhinitis with conjunctivitis & 17 & 7 & 24 \\
Rhinitis dermatitis & 2 & 2 & 4 \\
Rhinitis with pharyngitis & 2 & 3 & 5 \\
Only Rhinitis & 12 & 9 & 21 \\
Total & 80 & 45 & 125 \\
\hline
\end{tabular}


Table-IV

Prevalence of Atopic Asthma among the patients with Allergic Rhinitis $(n=125)$

\begin{tabular}{lccc}
\hline Age in years & \multicolumn{3}{c}{ Number of the patients } \\
& Male & Female & Total \\
\hline $01-10$ & 4 & 1 & 5 \\
$11-20$ & 5 & 4 & 9 \\
$21-30$ & 23 & 10 & 33 \\
$31-40$ & 9 & 3 & 12 \\
$41-50$ & 2 & 1 & 3 \\
$51-60$ & 2 & 2 & 4 \\
$60-80$ & 2 & 1 & 3 \\
\hline Total & 47 & 22 & $69(55 \%)$ \\
\hline
\end{tabular}

Table - V

Immunological status of the patients with allergic Rhinitis and Other allergies $(n=125)$

\begin{tabular}{llcl}
\hline Immunological Status & \multicolumn{3}{c}{$\begin{array}{c}\text { Number Percentage } \\
\text { of Patients }\end{array}$} \\
\hline Total Circulating & Increased & 103 & $82 \%$ \\
Eosinophil & Normal & 22 & $18 \%$ \\
Serum IgE titre & Increased & 85 & $68 \%$ \\
& Normal & 40 & $32 \%$ \\
Presence of & Found & 31 & $25 \%$ \\
Eosinophil in & Not found & 94 & $75 \%$ \\
nasal smear & & & \\
\hline
\end{tabular}

Table - VI

Immunological status of the patients with allergic rhinitis including atopic asthma

$$
(n=69)
$$

\begin{tabular}{llcl}
\hline $\begin{array}{l}\text { Immunological } \\
\text { Status }\end{array}$ & \multicolumn{3}{c}{$\begin{array}{c}\text { Number Percentage } \\
\text { of }\end{array}$} \\
\hline Total Circulating & Increased & 60 & $87 \%$ \\
Eosinophil & Normal & 9 & $13 \%$ \\
Serum IgE titre & Increased & 57 & $83 \%$ \\
& Normal & 12 & $17 \%$ \\
Eosinophil in & Found & 31 & $45 \%$ \\
nasal smear & Not found & 38 & $55 \%$ \\
\hline
\end{tabular}

Table - VII

Prevalence of respiratory symptomes among the asthmatic patients ( $n=69)$

\begin{tabular}{lcc}
\hline Symptomes & $\begin{array}{c}\text { Number of } \\
\text { the patients } \\
\text { suffering }\end{array}$ & Percentage \\
\hline Cough & 62 & $90 \%$ \\
Respiratory distress & 60 & $87 \%$ \\
Chest tightness & 69 & $100 \%$ \\
Wheeze & 15 & $22 \%$ \\
Stair test +ve & 58 & $85 \%$ \\
\hline
\end{tabular}

Table - VIII

Status of Eosinophilia among the patients with allergic rhinitis including atopic asthma $(n=60)$

\begin{tabular}{lccc}
\hline Level of the total & \multicolumn{3}{c}{ Number of the patients } \\
circuiting eosinophil & Male & Female & Total \\
\hline $401-500$ & 3 & 4 & 7 \\
$501-600$ & 2 & 3 & 5 \\
$601-700$ & 7 & 2 & 9 \\
$701-800$ & 4 & 5 & 9 \\
$801-900$ & 4 & 1 & 5 \\
$901-1000$ & 7 & 3 & 10 \\
$1001-1100$ & 3 & 1 & 4 \\
$1101-1200$ & 2 & - & 2 \\
$1201-1300$ & 1 & - & 1 \\
$1301-1400$ & 1 & 2 & 3 \\
$1401-1500$ & 1 & - & 1 \\
$1601-1700$ & 1 & - & 1 \\
$1701-1800$ & 1 & - & 1 \\
$1801-1900$ & 1 & - & 1 \\
$1901-2000$ & - & 1 & 1 \\
\hline Total & 38 & 22 & 60 \\
\hline
\end{tabular}


Table - IX

Status of Hyperimmunoglobulinemia (IgE) among the patients of Allergic Rhinitis including Atopic Asthma $(n=57)$

\begin{tabular}{lccc}
\hline Level of serum & \multicolumn{3}{c}{ Number of the patients } \\
IgE titre/IU & Male & Female & Total \\
\hline $100-200$ & 4 & 5 & 9 \\
$201-300$ & 8 & 1 & 9 \\
$301-400$ & 2 & 1 & 3 \\
$401-500$ & 5 & 1 & 6 \\
$501-600$ & 1 & 4 & 5 \\
$601-700$ & 4 & 2 & 6 \\
$701-800$ & 2 & 2 & 4 \\
$801-900$ & 2 & - & 2 \\
$901-1000$ & 1 & 2 & 3 \\
$1001-1100$ & - & 1 & 1 \\
$1101-1200$ & 1 & 1 & 2 \\
$1201-1300$ & 2 & - & 2 \\
$1301-1400$ & 2 & 1 & 3 \\
$1601-1700$ & - & 1 & 1 \\
$>2000$ & 1 & - & 1 \\
\hline Total & 35 & 22 & 57 \\
\hline
\end{tabular}

\section{Discussion:}

The international study of asthma and allergies in children noted the prevalence of allergic rhinoconjvactivitis in 6-7 years old as $0.8-14.9$ percent and in 13-14 years as 1.4-39.7 percent as different countries throughout the world ${ }^{5}$ with a significant correlation between the prevalence of asthma and rhinitis in school children. The Swiss study on Air pollution and lung diseases in adults noted the prevalence of allergic rhinitis as 13.5 percent(female 12.6 percent, male 14.3 percent $)^{6}$. Allergic rhinitis usually happens in over $65 \%$ of patients with allergic/atopic asthma and in over $80 \%$ of patients with nonallergic asthma ${ }^{1}$. The Copenhagen allergy study noted that 42-52 percent patients with rhinitis had asthma and more than 99 percent of patients with atopic asthma also had allergic rhinitis ${ }^{7}$. Both diseases frequently co-exist in the same patients, with asthma present in $20-50 \%$ of patients with allergic rhinitis and rhinitis present in upto $80 \%$ of patients with asthma challenging the nose with allergens will induce the influx of inflammatory cells in the lower airways and vice versa ${ }^{11}$. Positive family history is the best established risk factor of allergic diseases. Suggested possible environmental factors include life style changes, urbanization of non-westernized societies, increased exposure to allergens, pollutants and irritants, diminished protective nutrients, decrease in infections leading to a reduced Th 1-type immune response (the hygiene hypothesis) ${ }^{13}$ and stress. ${ }^{14}$ Air pollutants certainly increase symptomatic rhinitis and diesel exhaust particles may induce a Th2- like inflammation ${ }^{20}$; ozone may also be a relevant factor. ${ }^{21}$ Genes involved in allergic rhinitis and atopic asthma are located mainly on $5 \mathrm{q}$ chromosome, also on 11q, 13, 12q chromosome and regulate the production of concerned cytokines and chemical mediators ${ }^{15}$ .The CD14 gene maps to chromosome $5 \mathrm{q} 31$, a candidate region for loci regulating total serum $\lg \mathrm{E}^{36}$. Well known causative agents affecting both nose and bronchi are allergens and aspirin. ${ }^{16}$ All of the most common triggers of occupational asthma can induce occupational rhinitis and vice versa- asthma is more pronounced with low molecular weight agents whereas rhinitis with high molecular weight agents and this highlights the importance of ceasation of allergen exposure in allergic rhinitis in order to prevent asthma ${ }^{2}$. Rhinitis is a risk factor for the development of subsequent asthma and is a frequent cause of asthma exacerbations and there is evidence that rhinitis treatment reduces asthma. ${ }^{17}$ Onset of asthma was associated with allergic rhinitis - rhinitis increased the risk of asthma by about three times among both atopic and nonatopic patients and by more than five times among patients with higher IgE titre. ${ }^{34,35}$ Presence of diagnosed allergic rhinitis in infancy was associated with a doubling of the risk of developing atopic asthma by 11 years of age $^{18}$ whereas in adults, 10.5 percent of students diagnosed with allergic rhinitis went to develop asthma compared with $3.6 \%$ of those 
who did not have rhinitis ${ }^{19}$. Early life smoking in mothers or smoking during pregnancy is strongly associated with an incrcase in the prevalence of atopic sensitization, rhinitis and asthma. However, nasal mucosa is more exposed to noxious environment than the bronchial mucosa but epithelial shedding is more pronounced in the bronchi ${ }^{22}$. In patients with moderate to severe asthma, eosinophilic inflammation is more pronounced in bronchi than in the nose whereas in patients with mild asthma, the inflammation is similar in both sites; moreover, the inflammation in the nose exists in asthmatics with or without nasal symptoms. Central to the pathogenesis of rhinitis and asthma is the role of eosinophil and airway epithelium-after release of and differentiation of progenitor cells, eosinophil, basophil, mast cells are typically recruited to the inflammation tissue in atopic individuals, thus is the enhanced expression of IL- 5 in the nasal epithelium 24 hours after bronchial challenge and increased eosinophil in bronchial mucosa after nasal challenge. When exposed to water, pollen allergens are exposed into submicronic particles, the starch granules, which can reach the lower airway and induce asthma. A recent study shows that endobronchial allergen challenge induced nasal and bronchial symptoms along with reduction in pulmonary and nasal functions. ${ }^{24}$ Nasal viral infection both in children and adults exacerbates asthma ------------ rhinoviruses are the major cause and a trigger of acute asthma exacerbation. Diagnosis of allergic rhinitis is aided by thorough history taking including presenting respiratory symptomes, symptomes of co-morbidity, family history, occupational, environmental, dietary and drug use history, history of any nonallergic triggers - frequency, severity, duration, persistence, intermittence or seasonality of symptomes, quality of life, tratment expenditure should be quaried; a full ENT examination, chest examination with pulmonary function measurement ( peak flow, spirometry), search for atopic conjunctivitis and dermatitis; estimation of specific IgE level, total IgE level for complicated allergic rhinitis since $50 \%$ patients have normal IgE level in complicated cases ${ }^{25}$-other test like skin prick fest, normal allergen challenge test may be required. Treatment strategies should involve both upper and lower since the latter is also affected usually and a strategy of combining treatment of both airway diseases appears to be optimum in teams of both efficacy and safety ${ }^{1}$. The $2^{\text {nd }}$ generation antihistamines are appropriate for the treatment of atopy and amongst them cetirizine, desloratadine, loratadine, lovocetirizine, fexofenadine are appropriate having both antihistamine and anti-inflammatory effects; They apperer to be more effective if used regularly rather than intermittently ${ }^{26}$ and they may reduce allergic progression in children ${ }^{27}$ and use of levocetirizine and desloratadine in asthma has been recently reviewed specially ${ }^{37}$. The combination of oral antinistamine and decongestants was found more effective on asthma symptomes ${ }^{28}$. Anti-leukotriens are helpful for mild to moderate asthma and seasonal allergic rhinitis may be an alternative to or a combination with antihistamines but they got many hazardous side effects. Topical glucocorticoides are the most effective drugs for atopic asthma and rhinitis intranasal glucocorticoides for allergic rhinitis was found to improve asthma ${ }^{29,30}$ Intranasal corticoids reduce the relative risk of asthma exacerbation/ hospitalization by $50 \%$ or more if combined with antihistamine ${ }^{33}$ Beclomethasone, Triamcinolone. Momentasone are licensed from the age of six years, Fluticasone propionate from four, Fluticasone furoate from two and sodium cromoglycate is reserved for the younger age. Ketotifen, also azelastine and olopatadine, got the membrane stabilizing effect (mast cell, basoplil) as well as antihistamine effect. Oral steroides are the most effective treatment for allergic rhinitis and asthma but longterm use is contraindicated and are reserved only for complicated cases. In contrast to pharmacotherapy, immunetherapy offers more potential longterm modification and prophylaxis, and is reserved for only severe case of rhinitis and asthma and three years treatment for seasonal rhinitis in children resulted into tow or three fold reduction in risk of developing asthma ${ }^{31}$. Rhinitis increases the 
cost of asthma yearly medical charges for those with asthma and concomittant rhinitis were average $46 \%$ higher than for those with asthma alone. ${ }^{38}$

\section{Conclusion :}

Socioeconomic impact of allergic rhinitis should be assessed keeping the other associated conditions viz. asthma, dermatitis, sinusitis, otitis media, pharyngitis, sleep disorders, LRTI etc. in mind. Patients with both asthma and allergic rhinitis experience more physical limitations than patients with allergic rhinitis alone whose number is too low as well as rhinitis increases the costs of asthma. The epithelial-mesenchymal trophic unit exists from nose tow bronchiolar-alveolar junction and same inflammatory cells present thorought the airway suggests a continum of diseases. Rhinitis and asthma are linked by epidemiological and pathophysiological characteristics and by a common therapeutical approach. Wheather allergic rhinitis preceds asthma, triggers asthma or precipitates asthma are intuitive aspects that require supportive data.

\section{References:}

1. Bousquet J, Van Couwenberge P, Khaltaev N. Allergic Rhinitis and its impact on asthma. J Allergy Clin Immunol 2001; 108: S147-334.

2. Bousquet J, Vignola AM. The relationship between the upper and lower respiratory tract. Scott-Brown's otorhinolaryngology, head and neck surgery $7^{\text {th }}$ ed. Vol. 3. p.1560-1566

3. Aberg N, Hesselmer B, Aberg B, Eriksson B. Increase of asthma, allergic rhinitis and eczema in swedish schoolchildren between 1979 and 1991. Clin Exp Allergy 1995; 25: 815-9.

4. Leynaert B, Neukirch F, Demoly P, Bousquet J. Epidemiologic evidence for asthma and allergic rhinitis co-morbidity. J Allergy Clin Immunol 2000; 106: S 201-5.

5. Strachan D, sibbald B, weiland S, Ait-khaled N, Anabwani G, Aderson HR, et al. Worlduide variations in prevalence of symptomes of allergic rhinoconjunctivitis in children: the International study of Asthma and Allergics in childhood (ISAAC) Paediatr Allergy Immunol 1997; 8: 16176 .

6. Wuthrich B, Schindler C, Leuenberger P, Ackermann Liebrich U. Prevalence of atopy and pollinosis in the adult population of Switzerland.
Swiss study on Air Pollution and Lung Diseases in Adults. Int Arch Allegy Immunol 1995; 106: 149-56.

7. Linneberg A, Nielsen NH, Madsen F, Frolound 1, Dirksen A, Jorgensen T. Secular trends of allergic asthma in Danish adults. The Copenhagen Allergy study. Resp Med 2001; 95: 258-64.

8. Chanez P, Vignola AM, Vic P, et al. Comparison between nasal and bronchial inflammation in asthmatics and control subjects. Am J Resp Crit Care Med 1999: 159; 588-95.

9. Simons FE. Allergic rhinobronchitis: The asthma and allergic rhinitis link. J Allergy Clin Immunol 1999; 104: 534-40.

10. Leynaert B, Bousquet J, Neukirch F, et al. Perennial rhinitis; An independent risk factor for asthma in nonatopic subjects: Result from the European Community Respiratory Health Survey. J Allergy Clin Immunol 1999; 104: 301-4.

11. Bourdin A, Gras D, Vachier I, et al. Upper airway1: Allergic rhinitis and asthma: united disease through epithelial cells. Throax 2009; 64: 9991004.

12. Barnes K, Marsh D. The genetics and complexity of allergy and asthma. Immunology Today 1998; 19: 325-32.

13. Butland BK, Strachan DP, lewis S, Bynner J, Butler N, Britton J. Investigation into the increase in hay fever and eczema at age 16 obeserved between 1958 and 1970. British birth cohorts. BMJ 1997; 315: 717-21.

14. Scadding G, Durham S. Allergic Rhinitis. ScottBrown's otorhinolaryngology, head and neck surgery $7^{\text {th }}$ ed. Vol. 3. p.1386-1402.

15. Fujieda S, Diaz- Sanchez D, Saxon A. Combined nasal challenge with diesel exhaust particles and allegren induces in vivo $\lg \mathrm{E}$ isotype switching. Am J Resp Cell Mol Biol 1998; 19: 507-12.

16. Graham DE, Kuren HS. Biomarkers of inflammation in ozone-exposed humans. Comparison of the nasal and bronchoalveolar lavage. Am Rev Resp Dis 1990; 142: 152-6.

17. Murray CS, Pipis SD, McArdle EC, Lowe LA, Custovic A, Woodcock A. Lung function at one month of age as a risk factor for infant respiratory symptomes in a high risk population. Thorax 2002; 57: 388-92.

18. Holgate ST, Asthma genetics - Waiting to exhale? Nature genetics 1997; 15: 227-9.

19. Szczeklik A, stevenson DD Aspirin-induced asthma: advances in pathogenesis and management. J Allergy Clin Immunol 1999; 104: $5-13$. 
20. Ragab S, Scadding GK, Lund VI, Saleh H. Treatment of chronic rhinosinusitis and its effect on asthma. European Resp J 2006; 28: 68-74.

21. Wright Al, Holberg CI, Martinez FD, Haloren M, Morgan W, Taussing LM. Epidemiology of physician-diagnosed allergic rhinitis in childhood. Paediatrics 1994; 94: 895-901.

22. Settipane RJ, Hagy GW, settipane GA, Long-term risk factors for developing asthma and allergic rhinitis: a 23- year follow-up study of college students. Allergy Proceedings 1994; 15: 21-5.

23. Suphioglu C, Singh MB, Taylor P, Belloma R, Holmes P, Puy R, et al. Mechanism of grass-polleninduced asthma. Lancet 1992; 339: 569-72.

24. Newman LJ, Platts-Millis TA, Phillips CD, Hazen KC, Gross CW. Chronic sinusitis. Relationship of computed tomographic findings to allergy, asthma, and eosinophilia. JAMA1994; 271: 3637 .

25. Johnstone SL, Pattemore PK, Sanderson G, Smith $\mathrm{S}$, Campbell MJ, Josephs LK, et al. The relationship between upper respiratory infections and hospital admission for asthma a time trend analysis. Am J Resp Crit Care Med 1996; 154: 654-60.

26. Ciprandi G, Passalacqua G, Mincarini M, Ricca V. Canonica GW. Continuous versus on demand treatment with cetirizine for allergic rhinitis. Ann Allergy Asthma Immunol 1997; 79: 507-11.

27. ETAC R study group. Allergic factors assoriated with the development of asthma and the influence of cetirizine in a double-blind, randomised placebocontrolled trial: first result of ETAC R. Paediatr Allergy Immunol 1998; 9: 166-24.

28. Corren J, Harris AG, Aaronson D, Beaucher W, Berkowitz R, Bronsky E, et al. Efficacy and Safety of loratadine plus pseundoephedrine in pationts as with seasonal allergic rhinitis and mild asthma. J Allergy Clin Immunol 1997; 100: 7818 .

29. Watson WT, Becker AB, Simons FE, Treatment of allergic rhinitis with intranasal corficosteroides in patients with mild asthma: effect on lower airway responsiveness. J Allergy Clin Immunol 1993; 91: 97-101.

30. Pedersen B, Dahl R, Lindquist N, Mygind N. Nasal inhalation of glucocosticoid budesonide from a spacer for the treatment of patients with pollen rhinitis and asthma. Allergy 1990; 45: 451-6.

31. Moller C, Dreborg S, Ferdousi HA, Halken S, Host A, Jacobson L, eat al. Pollen immunotherapy reduces the development of asthma in children with seasonal allergic rhinoconjunctivitis. J Allergy Clin Immunol 2002; 109: 251-6.

32. Crystal Peters J, Neslusan C, Crown WH, Torres A. Treating allergic rhinitis in patients with comorbid asthma: the risk of asthma related hospitalizations and emergency department visits for asthma. J Allergy Clin Immunol 2000; 109: 57-62.

33. Adams RJ, Fuhlbrigge AL, Finkelstein JA, Weiss $\mathrm{ST}$, International steroids and the risk of emergency department visits for asthma. J Allergy Clin Immunol 2002; 109: 636-42.

34. Plaschke PP, Janson C, Norrman E, Bjornsson E, Ellbjar S, Jarrholm B. Onset and remission of allergic rhinitis and asthma and the relationship with atopic sensitization and smoking. Am J Resp Crit Care Med 2000; 162: 920-4.

35. Guerra S, Sherrill DL, Martinez FD, Barbee RA. Rhinitis asan independent risk factors for adultonset asthma. J Allergy Clin Immunol 2002; 109: 419-25.

36. Baldini M, Lohman IC, Halonen M, Erickson RP, Holt PG, Martinez FD. A polymorphism in the $5 \$$ flanking region of the CD14 gene in association with circulating soluble CD14 levels and with total serum IgE. Am J Resp Cell Mol Biol 1999; 20: $976-83$.

37. Wilson AM. Are antihistamines useful in managing asthma? Curr Opin Allergy Clin Immunol 2002; 2: 53-9.

38. Yawan BP, Yunginger JW, Wollan PC, Reed CE, silverstein Md. Harris AG. Allergic rhinitis in Rochester, Minnesota residents with asthma: frequency and impact on health care charges. J Allergy Clin Immunol 1999; 103: 54-9. 